\title{
El Comercio de Gijón: un diario local asturiano frente a la cuestión carbonera en torno a la Primera Guerra Mundial
}

\author{
Jorge MuÑIZ SÁNCHEZ \\ Universidad de Oviedo \\ jorgemunizsanchez@gmail.com
}

Recibido: 30 de mayo de 2014

Aceptado: 3 de septiembre de 2014

\section{Resumen}

La prensa regional es a menudo representante de los intereses económicos de grupos locales que determinan su línea editorial. En algunos casos lo hacen de forma genérica y en otros muy directa, específica e involucrada. Esto último es lo que sucede con el problema hullero y el periódico gijonés El Comercio en la Primera Guerra Mundial y los años veinte. Sin embargo, esta es una época en la que se afirma en general la prensa de masas y en particular esta cabecera como diario comercial que se presenta a sus lectores, en consonancia, como una publicación preocupada exclusivamente por el bien común.

Palabras clave: El Comercio; hulla; Gijón; periodismo; I Guerra Mundial.

\section{El Comercio from Gijón: a local newspaper about the coal question around the World War I}

\begin{abstract}
Regional press is often representative of the economic interests of local groups that determine its editorial line. In some cases, they do it in a general manner and in others, in a straightforward and involved way. The latter is what happens with the coal problem and the newspaper El Comercio from Gijón in the World War I and the 1920s. However, this is a time when the mass print media in general, and this newspaper in particular, are reinforced, presenting themselves as publications solely concerned with the common good.
\end{abstract}

Key words: El Comercio; coal; Gijón; Journalism; World War I.

\section{Referencia normalizada}

Muñiz Sánchez, J. (2014). El Comercio de Gijón: un diario local asturiano frente a la cuestión carbonera en torno a la Primera Guerra Mundial. Historia y Comunicación Social. Vol 19, páginas 33- 45.

Sumario: 1. Introducción. 2. Un diario local, conservador e independiente. 3. La cuestión hullera. 4. Conclusión. 5. Referencias bibliográficas. 


\section{Introducción}

En estas páginas se pretende ofrecer una visión hasta ahora inédita de la prensa local gijonesa y concretamente del diario El Comercio. Si bien existen estudios sobre su evolución, su línea editorial y otros aspectos en absoluto exentos de interés pero en cambio bastante genéricos, no sucede lo mismo con un análisis de su posición con respecto a lo que se conoció como "cuestión hullera". Sin embargo, es esta, como se comprenderá fácilmente, una materia de capital importancia para la vida de la región durante el primer tercio del siglo XX, dado el peso que en el conjunto de su economía tenía tal actividad. Por otra parte, los propósitos del mencionado periódico al respecto están profundamente influidos por la composición y los intereses directos de su accionariado a pesar de no estar este ligado a la minería, lo cual supone una especificidad que le confiere una relevancia adicional. Precisamente por esto, amén de las obvias limitaciones de tiempo y espacio, no es la intención de este artículo agotar el tema ni extrapolar sus conclusiones a otras cabeceras asturianas, algo que a todas luces podría considerarse cuando menos aventurado en términos generales y especialmente a la vista de las peculiaridades indicadas. Esta labor, de mucho más amplio alcance, resultaría de sumo atractivo por el valor que siempre tiene un estudio comparativo, además de la ya señalada trascendencia de los acontecimientos históricos implicados en el desarrollo de la región. Cabe desear que la historiografía avance en este terreno en los próximos años.

Por tanto, a la espera de futuras investigaciones sobre la posición de otras cabeceras en el terreno hullero, nos limitaremos al rotativo de referencia, tratando de poner en relación las variables que en ambos temas concurren y explican su desarrollo. Para ello contamos con bibliografía solvente. Como se ha indicado ya, sobre el propio periódico existe un corpus de cierta entidad que permite situar la publicación en unas coordenadas generales (Mato et alii, 2003; Fernández Vega, 2004; Muñiz Sánchez, 2007). Puede citarse también alguna obra con perspectiva globalizadora digna de mención a propósito de la prensa en Asturias (Fernández Avello, 1976; Santullano, 1978; Uría, 2004). Distinto es el caso de la minería porque, como es sabido, la producción escrita al respecto es bastante nutrida. Desde las obras coetáneas, producto del trabajo de los ingenieros de minas y gestores empresariales o políticos de la época (Adaro y Magro, 1911; Aldecoa, 1926), pasando por la prensa militante de las organizaciones de izquierda y las obras de sus dirigentes (Llaneza, 1985) hasta la moderna historiografía social, que ha ofrecido frutos relativamente abundantes y, sobre todo, de una calidad en general muy alta y una perspectiva multidisciplinar (Moradie1los, 1986; Sierra Álvarez, 1990; García García, 1996). Sin embargo, los aspectos económicos de la explotación siguen siendo un territorio poco explorado (Díaz-Faes Intriago, 1979; Ojeda, 1985) y la evolución técnica de la misma es prácticamente terreno virgen a día de hoy. Ambos resultarían mucho más cercanos y útiles para nuestros fines aquí. Sea como fuere, la fuente principal sobre la que se ha trabajado la constituye, como no podría ser de otro modo, el propio diario. 


\section{Un diario local, conservador e independiente}

Como ha sido señalado en algún estudio sobre el particular, El Comercio formó parte desde sus orígenes de la prensa local independiente asturiana. Obviamente, un epíteto tan equívoco y frecuentemente violentado requiere una matización. No era el órgano de expresión de ninguna corriente política, o al menos no de forma abierta y permanente, y debía su existencia a su orientación al gran público, en una época en la que los periódicos de información irán paulatinamente superando en número y circulación a los de carácter político. Nacía, por tanto, la prensa de masas (Desvois, 1977: 161). Esto requería una no adscripción política o partidista explícita, que permitiera acceder a sectores de potenciales lectores lo más amplios que fuera posible, algo siempre muy tenido en cuenta por esta empresa editorial (Fernández Vega, 2004; Muñiz Sánchez, 2007). Sin embargo, esto no quiere decir que no tuviera sus inclinaciones, que más que a ideologías correspondían a intereses y no eran inquebrantables sino más bien cambiantes en función de las coyunturas. Esto explica que la crisis de la Restauración se llevara por delante sus oscilaciones entre uno y otro partidos turnantes para desembocar en un reformismo circunstancial no falto de grandes panegíricos a la figura de su líder, el gijonés Melquíades Álvarez, y otros dirigentes locales como el avilesino José Manuel Pedregal (El Comercio, 25-3-1916). A nadie escapará que el origen asturiano de Álvarez e incluso el carácter relativamente endémico que tuvo su formación en la región (Oliveros, 1947: 40; Íñigo Fernández, 2000: 55) constituirían acicates indudables para que un rotativo tan atento a los intereses económicos como lo era el que nos ocupa le otorgara su apoyo. Un incentivo primordial de las mencionadas loas sería la esperanza de que el reformismo pudiera convertirse de algún modo en una herramienta semejante a la que constituían los partidos regionalistas o nacionalistas periféricos que existían en otros lugares, y que tan bien representaban los anhelos de una cierta burguesía provincial. Esto no fue óbice para que, llegado el momento y reunidas las circunstancias, el diario abominara del reformismo por considerarlo demasiado tolerante con la temida conflictividad social y virara con decisión hacia el primorriverismo inicialmente y el cedismo después (El Comercio, 14-9-1923, 14-2-1925..., Muñiz Sánchez, 2007: 486-493).

Dentro de esta estrategia comercial se enmarcan en toda lógica las transformaciones que sufre el periódico y que apuntan en la dirección de hacerlo más apto para el gran público, más atractivo y competitivo en relación a sus concurrentes. A las modificaciones en este sentido de 1911 (Fernández Vega, 2004: 170-171) les siguen las de la época de la Primera Guerra Mundial y culminan a partir de 1919 con un cambio de formato marcado por la compra de cuatro máquinas de componer que posibilitaban la confección de números más amplios y una portada que cada vez se asemeja más a un escaparate, con mayor número y tamaño de titulares. Igualmente, comienza a ocupar un espacio destacado cuantitativa y cualitativamente el deporte y en particular y no por casualidad el que está llamado a convertirse en masivo en este período: el fútbol. A la inclusión de crónicas de los partidos (El Comercio, 21-11-1916) le seguirán la información previa a los mismos y otras adicionales ya en los años treinta. La década de 1920 verá aumentar también la carga gráfica de la publicación, con viñetas 
humorísticas y, sobre todo, con la aparición de fotografías en sus páginas, que pasan de los retratos de grandes personajes en el verano de 1920 a las de eventos deportivos un año después. Todo ello contribuye, evidentemente, a hacer más asequible el diario para amplios sectores de la población que no contaban con una cultura elevada.

Se trata también de un rotativo marcadamente local, algo que está en perfecta consonancia con su carácter de portavoz de los intereses de una burguesía comercial gijonesa a la que nos referiremos más adelante. En buena lógica, la atención preferente prestada a la economía comarcal se plasmaba en la cobertura de la política municipal, que fue la vedette de este ámbito salvo durante la Segunda República, cuando los problemas nacionales adquirieron un protagonismo no exclusivo, pero sí ampliamente mayoritario (Muñiz Sánchez, 2007: 489-494). Sus preocupaciones básicas fueron tres: la traída de aguas, la pavimentación y el alcantarillado y, por supuesto, la financiación (El Comercio, 26-5-1917, 27-5-1917, 29-5-1917, 3-9-1917, 7-11-1917, 12-2-1928, 21-2-1930...). La situación del firme de las calles comenzó a estar presente en sus páginas casi permanentemente a finales de 1916, argumentando que lo que entonces era fácil y económico arreglar terminaría suponiendo un grave gasto si se permitía que continuara el deterioro (El Comercio, 26-12-1916). Se lamentaba ante todo - aunque también irritaba el entorpecimiento de la circulación- el estado de las calles cercanas a la playa, que eran las más concurridas por los veraneantes (El Comercio, 22-1-1917, 21-3-1917...). Realmente, el aspecto de la vía pública debió ser deplorable, porque, de forma especialmente gráfica y explícita, se emitieron amargas quejas por la reaparición de las madreñas — que se creían desterradas del casco urbano - a causa del mal estado del suelo, ya que "con su música se le da a este pueblo el carácter de una villa de tres al cuarto" (El Comercio, 28-3-1917). En ocasiones las protestas del diario adoptaban un tono humorístico e incluso versificado: "Sin precisar de una sonda, / podemos decir muy alto: / - ¡No hay un pedazo de asfalto / sin una tumba muy honda!" (El Comercio, 22-1-1917 o 21-3-1917).

Así las cosas, en las postrimerías de la Gran Guerra se invitó al debate un elemento de preocupación añadido: la muy mortífera pandemia conocida como "gripe española". Desde entonces, se constituirá prácticamente en el único argumento para exigir una mejora de las calles, dado que en las mismas se acumulaban polvos y otros residuos que podían ser portadores del mal. Se censuró, por ejemplo, el poco caso que se hizo del informe del Dr. Ealo, en junio de 1918, sobre el peligro que representaba la situación de los viales (El Comercio, 8-6-1918). Las razones aludidas estaban, lógicamente, muy embebidas en las teorías médico-sociales de la época, en particular el higienismo, que daba una gran importancia a la calidad del aire: "Ese lodo, ¿no será cuando se seque polvo asfixiante, cargado de miasmas que con los vientos primaverales, tan característicos en Gijón, nos envuelvan, nos ahoguen y nos maten?" ( $E l$ Comercio, 4-3-1919). La presencia de tales propósitos en las topografías médicas de la época es muy expresiva (Portolá, 1918). Las críticas al respecto en el diario sólo empezaron a remitir en la época de la dictadura de Primo ("Continúa con ejemplar constancia la labor de arreglo de las calles", El Comercio, 14-1-1925). 
También en la polémica en torno a la traída de agua a la ciudad resultó un elemento central la cuestión sanitaria. No en vano, fue la epidemia de tifus de 1911 la que hizo plantearse en Gijón la necesidad de cambiar el sistema existente (El Comercio, 2-111914 y 8-11-1914). La disyuntiva se estableció entre el manantial de El Peranchu (en el cercano concejo de Nava) y la completa adquisición del de Llantones (Gijón), que era el que entonces abastecía la ciudad, confiando en que pudiera aumentarse su potabilidad, cuestionada a causa del tifus. Mientras los peranchistas se basaban en la supuesta insalubridad de la fuente entonces empleada, la principal baza de los llantonistas fueron las dificultades legales que presentaba la opción naveta, puesto que al parecer se auguraba un proceso expropiatorio largo y difícil (El Comercio, 12-6-1915). Los ataques furibundos del llantonista El Comercio fueron dirigidos, en este asunto como en tantos otros, contra los concejales del Partido Reformista, que en su opinión estaban defendiendo sus negocios en contra de los intereses públicos, insinuando sin demasiadas cautelas que obtendrían ganancias con El Peranchu ( $E l$ Comercio, 22-8-1923). En contrapartida, El Noroeste, vocero del reformismo, culpó a El Comercio — que en 1923 seguía oponiéndose a la fuente de Nava pero ya no veía factible seguir con la de Llantones- de haber abogado en el pasado por el manantial gijonés sólo para favorecer a un dueño de molinos en la zona que había sido copropietario del periódico (El Noroeste, 22-8-1923, y El Comercio, 23-8-1923).

Se puede comprobar entonces como, de nuevo, los otros negocios de los grandes accionistas del diario estaban continuamente presentes en el día a día de este. Las duras diatribas de El Comercio en este asunto se radicalizaron durante el año veinticuatro y terminaron incluso por atraer la censura sobre el mismo. El 18 de septiembre reclamó que el Ayuntamiento adquiriera concesiones libres de abastecimiento, en términos apremiantes, antes de que lo hicieran particulares para vendérselas después. Al día siguiente, criticó a la Comisión Permanente por inactividad y por haber encargado otro informe técnico que se consideraba inútil y que en su opinión sólo habría de retrasar el proceso. A continuación, el día 20, advertía de que "Por causas ajenas a nuestra voluntad no nos es posible publicar nuestro editorial de hoy". Terminó imponiéndose la opción de El Peranchu en un proyecto mixto que contemplaba también la traída complementaria desde la Fuentona de los Arrudos (El Comercio, 6-2-1927).

Existió un tercer gran tema de índole municipal tratado preferentemente en las páginas de El Comercio: los problemas presupuestarios, muy relacionados como es obvio con los señalados anteriormente. Se pensaba que el Estado había dejado inermes a los ayuntamientos al no dispensarles las ayudas ofrecidas y que era necesario cambiar el régimen contributivo a través de un aumento de la autonomía económica municipal (El Comercio, 27-7-1917 y 13-10-1917). Es curioso y poco alentador comprobar que, casi un siglo después, la cuestión de la financiación municipal parece irresoluble o, al menos, permanece irresoluta. En el caso histórico que nos ocupa, $E l$ Comercio achacaba el déficit a la mala administración y a la abolición del impuesto de consumos sin sustituirlo por otros, como por ejemplo uno sobre la exportación de pescado, que decía no se aplicaba para no "molestar los intereses de correligionarios o amigos" (El Comercio, 7-12-1917). En contra de dicha abolición se alegaba que, al 
poder los vendedores ir y venir al mercado sin pagar portazgos, si no obtenían por sus productos el precio deseado volvían a sus casas con ellos, circunstancia que anteriormente no se producía debido a las multiplicación de tasas que generaba. Es decir: la supresión de estas cargas sobre los productos de primera necesidad en realidad habría contribuido a encarecerlos, dentro de la espiral hiperinflacionista que acompañó a la Gran Guerra. Un argumento a todas luces poco creíble. Tampoco este asunto quedó libre de implicaciones políticas. Los industriales del pescado fueron acusados de utilizar El Noroeste para obstaculizar el establecimiento de este gravamen, favor que habrían de pagar en forma de donaciones en época electoral (El Comercio, 6-6-1918). No se hicieron acreedores de mejor opinión los concejales que se opusieron al impuesto con afanes tildados de subversivos. De nuevo se transparentaba, de este modo, el miedo a disturbios graves generados por los intentos de utilización política del elemento obrero por parte de sectores de la burguesía progresista. Precisamente el tipo de denuncia que había llevado a El Comercio unos meses antes al ya mencionado cambio de línea editorial que le había alejado para siempre del Partido Reformista (El Comercio, 13-6-1918).

\section{La cuestión hullera}

Como se habrá apreciado ya en las páginas precedentes, si las cuestiones locales ocupan un lugar central entre las preocupaciones del diario el responsable último de la mayor parte de las mismas no sale por lo común muy bien parado. El ayuntamiento constituye, en efecto, la diana preferida de sus dardos por considerar que hacía dejación de sus responsabilidades y que por ello Gijón navegaba "a la deriva" (El Comercio, 17-4-1935). Estas críticas son comprensibles porque durante mucho tiempo la fuerza hegemónica en el mismo fue el Partido Reformista, al que El Comercio se aproximó en sus inicios y denostó ampliamente a partir de 1917. Otras instancias locales tampoco estuvieron a salvo de tales acometidas: la Cámara de la Propiedad Urbana, por ejemplo, fue acusada de incapacidad sin obtener satisfacción a sus pretensiones (El Comercio, 8-8-1930, 26-9-1930, 3-10-1930, 25-11-1930, 27-111930, 29-11-1930, 27-8-1931, 29-8-1931, 10-11-1931, 11-11-1931). Ni los diputados asturianos en Cortes escaparon a las recriminaciones del diario a propósito de su pasividad ante tratados comerciales con Uruguay y Holanda que perjudicaban al sector pecuario regional (El Comercio, 27-7-1933, 26-1-1934, 7-7-1934). Las repercusiones para el sector ganadero se hacían notar sin duda en el puerto de mar de la ciudad, en el que algunos de los accionistas de referencia del periódico tenían intereses (Alvargonzález, 1985: 45-49, Santullano, 1978: 149, Fernández Vega, 2004: 177) como se indicará más adelante. Este hecho es la clave que explica no sólo esta posición en concreto, sino también otras muchas relacionadas con sectores económicos que no afectaban directamente a Gijón pero que encontraban en su dársena la salida a sus productos, como es el caso crucial del carbón del que más tarde nos ocuparemos. 
Sin embargo, la mayor campaña sostenida por el periódico durante esta etapa fue contra la desmesurada inflación que hacía casi inaccesibles los productos de primera necesidad y cuyas causas iniciales hay que buscar en la Primera Guerra Mundial. El objetivo de la misma fue, cómo no, el ayuntamiento, al que se acusó de inhibirse. La preocupación del periódico giraba, una vez más, en torno a la competitividad de las empresas locales, que se veían obligadas a mantener sueldos altos para posibilitar la mera supervivencia de sus trabajadores. Esto iba en detrimento del comercio local y era causa de los desvelos del rotativo. Claro que la posibilidad de que llegara a producirse un estallido social tampoco era una motivación menor. La queja más habitual en sus páginas fue que esta carestía, que se extendió entre 1915 y 1923 , se veía agravada en Gijón por la acción de especuladores que inflaban artificialmente los precios, por lo que debían adoptarse medidas como la fijación de valores máximos para la venta de las diferentes mercancías (El Comercio, 14-10-1915, 18-9-1917, 19-9-1917, 26-91917...; Muñiz Sánchez, 2007: 482-484).

Como se adelantaba anteriormente, una de las principales preocupaciones que en este ámbito demostró la publicación fue la salud de la industria minera regional. Tal empeño se manifestaba en la atención prestada a las noticias de la cuenca minera, privilegiadas a menudo en su segunda página y servidas por su corresponsal en Sama de Langreo, Alfonso Muñoz de Diego (El Comercio, 19-6-1914, 10-6-1915, 5-7-1915...). En el mismo sentido cabe interpretar que cuando las colaboraciones de ciudadanos destacados se hicieron frecuentes en la sección "Tribuna Libre" en la primera posguerra mundial una de las cuestiones más tratadas fuera precisamente la hullera. Esto en principio podría resultar un tanto sorprendente si se tiene en cuenta que en el municipio no existieron explotaciones carboníferas en el período aquí estudiado. La primera mina en el concejo será la de La Camocha en 1935 (García Quirós y Flores Suárez, 2000: 20-23 y 79; Alvargonzález, 1977: 38-39). En realidad, la actividad extractiva en sí era tan secundaria para Gijón como para el periódico, cuyo interés radicaba en la evacuación de la hulla por vía marítima, de la que la villa era la principal beneficiaria gracias a las comunicaciones ferroviarias establecidas con Langreo a mediados del siglo XIX y a su inacabado puerto exterior, El Musel. En efecto, Gijón era el lugar natural de embarque del carbón de las cuencas interiores gracias la Carretera Carbonera (desde 1842) y a los 34 kilómetros del Ferrocarril de Langreo, que la empresa del marqués de las Marismas acabó de construir en 1856 para dar fácil salida a sus carbones (Ojeda, 1985: 22-23 y Flores Suárez, 2004: 19-47).

Hay que reseñar, a propósito del puerto exterior, que El Comercio no había sido precisamente entusiasta del mismo y sí defensor de posiciones "apagadoristas", es decir, de la ampliación de la dársena interior. La polémica que al respecto se mantuvo y las posiciones del rotativo en la misma, apoyando las tesis de los navieros locales, son sumamente ilustrativas de cuáles eran los intereses del diario. No en vano, algunos de los más importantes armadores, como Óscar Olavaria o la familia Alvargonzález, eran socios fundadores de El Comercio. Por el contrario, los industriales mineros estaban más preocupados por mejorar las condiciones de embarque que en mantener el statu quo en la villa (Alvargonzález, 1985: 45-49, Santullano 1978: 149, 
Fernández Vega, 2004: 177). Con todo, el estado de las comunicaciones entre Gijón y las zonas productoras de combustible distaba de resultar satisfactorio para el periódico. En cierto modo, a las insuficiencias históricas de los transportes asturianos vino a sumarse la coyuntura bélica que determinó, incrementando la demanda súbita y brutalmente, una mayor escasez de vagones de mercancías. Por eso El Comercio exigió enérgicamente que el Ferrocarril del Norte habilitara más, ya que estimaba que se cargaba sólo un cuarenta por ciento del carbón que hubiera sido necesario. El resto, por supuesto, constituía un lucro cesante para el sector naval gijonés. Todo ello fue acompañado de una campaña para obtener la electrificación de la rampa ferroviaria del puerto de montaña de Pajares, que comunicaba la región con la Meseta y cuya consecución se debe a Francesc Cambó (El Comercio, 1-11-1916, 2-10-1916, 15-101916, 30-6-1918).

Así, la cuestión carbonera será tratada en el diario siempre desde un punto de vista principalmente interesado en su dimensión comercial, que era la que atañía a los sectores que defendía y que, al contrario que los de la política partidista, permanecerán absolutamente estables a lo largo de todo este período. Durante la Primera Guerra Mundial, época de oportunidades para la hulla asturiana debido a la desaparición temporal de las hullas extranjeras tradicionalmente competidoras de las nacionales, El Comercio sostuvo, como tantos otros, que era imprescindible aprovechar la coyuntura al máximo. Al inicio de la guerra publicó dos colaboraciones destacadas del facultativo de minas Julián G. Muñiz, autor con cierto renombre en lo tocante al problema minero en la época. En ellas se criticaba la falta de medios de transporte suficientes para colocar en el mercado toda la producción, la ausencia de aranceles al carbón inglés y la extendida idea de que las hullas asturianas eran de baja calidad, asuntos todos muy comentados en esas fechas (El Comercio, 6-12-1914 y 16-11915). Estos y otros aspectos serían tratados de nuevo por el citado García Muñiz en un libro aparecido en 1930 con el título La industria hullera. El proteccionismo era en realidad innecesario porque en el contexto bélico, con muchas cuencas europeas paralizadas, la competencia era escasa. Sin embargo, sí era útil defender la calidad del carbón regional, precisamente porque a menudo no era buena en aquellos días, debido a la puesta en explotación con métodos artesanales de yacimientos marginales al calor de los altos precios alcanzados por el mineral (Díaz-Faes Intriago, 1979: 81-92). En cualquier caso, que las ideas de un reconocido republicano progresista como García Muñiz encontraran eco en las páginas de El Comercio habla a las claras de que por entonces todavía no se había producido la ruptura del diario con el reformismo.

Esta perspectiva puramente comercial del problema minero, basada en los intereses navieros de la localidad, se manifestó durante toda la guerra mediante aceradas críticas a los concesionarios de yacimientos que los mantenían sin explotar en tan favorable contexto. En semejante dirección apuntaban artículos como "Los latifundios del subsuelo", firmado por Manuel G. Tuñón (El Comercio, 7-6-1915: 1). Sin embargo, parece evidente que quienes en tal situación de altísima rentabilidad no ponían a producir sus concesiones debían experimentar alguna dificultad irresoluble. 
Además, esto no hace sino confirmar la presunción de que el interés del diario pasaba por el transporte del carbón y no por su producción, ya que ese eventual aumento por extensión de la superficie explotada que defendía con vehemencia suponía un incremento de la competencia dentro del sector energético. Cabría incluso preguntarse hasta qué punto el acusado neutralismo de El Comercio no sería producto de tales perspectivas de negocio para el sector naval en la ciudad. Por ejemplo, en su sección "Divagaciones", el popular Alfredo García, Adeflor, criticaba sin piedad a quienes a su parecer vendían su pluma para tratar de crear un estado de opinión favorable a la entrada de España en la guerra en uno u otro bando (El Comercio, 7-6-1915).

Tras el conflicto se produjo un cambio totalmente lógico en las preocupaciones del diario, al menos si se contempla en la clave indicada. Comenzó a criticar a los industriales mineros por mantener precios altos (El Comercio, 7-10-1919), lo que redundaba en una menor competitividad de actividades económicas locales dependientes de la hulla, como el metal o el vidrio, a todas luces más próximos al conglomerado industrial gijonés cuya representación asumía el periódico. También propiciaría un descenso de las ventas perjudicial para los armadores locales... Esto no fue óbice, en cualquier caso, para que El Comercio tomara partido por la patronal minera en detrimento de los trabajadores, puesto que abogó firmemente por el abaratamiento de la mano de obra para disminuir dichos precios. Olvidaba el diario conservador que ese aumento de la productividad podía lograrse también mediante una inversión en modernización técnica de las explotaciones que nunca llegó porque las empresas prefirieron embolsarse íntegramente los enormes beneficios de la guerra, sin reinvertir apenas nada. La acusación de bajo rendimiento formulada por el periódico contra los mineros y su defensa del aumento de jornada generó una polémica con El Socialista (El Comercio, 16-10-1924, 19-10-1924, 21-10-1924, 23-10-1924, 7-11-1924 o 20-10-1925, entre otros).

Hubo más ocasiones en las que El Comercio defendió las tesis de los empresarios del carbón, como durante la crisis postbélica que experimentó el sector a principios de la década de 1920 como consecuencia de su escasa competitividad (García Delgado, 1977). Esto se manifestó de tres formas básicamente: exigiendo la supresión de la prohibición de exportar carbones decretada durante la grave escasez de la Gran Guerra (El Comercio, 15-5-1921), denunciando el abastecimiento de la Marina con hulla foránea (El Comercio, 9-10-1921) y defendiendo la cartelización del sector con mediación del gobierno (El Comercio, 2-12-1921). Para completar el panorama, a pesar de ser "enemigos declarados de monopolios y absurdos proteccionismos", exigieron la elevación de los aranceles para combustibles extranjeros. En esto encontraron extraños compañeros de viaje, como el Sindicato Minero dirigido por Manuel Llaneza, aunque el corporativismo de este último hace menos inesperada su participación en el lobby, que además no fue la única como veremos más adelante (Moradiellos, 1986: 61). Que las ideas librecambistas del diario casaban mal con esta petición y creaban una contradicción en su seno es manifiesto por la propia aclaración introducida espontáneamente y porque en el mismo artículo se prodiga un encendido ataque al textil catalán, tenido por ejemplo de proteccionismo absurdo, habida cuenta 
de que éste - que gozaba de mayores favores gubernamentales - tenía que importar incluso la materia prima, mientras la hulla asturiana era en sí misma riqueza natural del país (El Comercio, 9-10-1921). En suma, lo que se venía a sostener es que hay proteccionismos tolerables en determinadas circunstancias y otros abominables en cualquier caso.

Sea como fuere, deben contemplarse estas arremetidas en el contexto del movimiento nacionalista del carbón que, impulsado fundamentalmente por la Asociación Patronal de Mineros Asturianos y favorecido por el momento político internacional, tuvo su concreción principal en los informes de la Comisión de Estudio de la Riqueza Hullera Nacional (Díaz-Faes Intriago, 1979: 85-86). Este clima está probablemente en el germen de las críticas de la publicación a determinadas decisiones de la Junta de Aranceles o a un tratado con el Reino Unido que rebajaba las tasas para la hulla británica y ante el que llamó a "una acción vigorosa sin distinción de clases sociales" (El Comercio, 27-7-1922). En cualquier caso, no parece que esta actitud sea privativa del período aquí en cuestión, puesto que se ha señalado ya para mediados del XIX un titubeo permanente en el diario entre la ortodoxia ideológica librecambista y la realidad de un sector clave para la economía regional incapaz de competir en igualdad de condiciones con el extranjero (Fernández Vega, 2004: 175).

Tales cambios de opinión se manifestarán de nuevo en 1924 sin que hayamos encontrado para ello una explicación clara, empezando entonces a criticarse lo que se entendía apatía de los implicados por encontrar siempre la comodidad de las ayudas estatales. Lo que se exigía poco antes volvía a resultar inadmisible, se denunciaba la imprevisión en la época favorable que previamente se había ignorado y se pedía a la patronal que realizara esfuerzos de reorganización del sector para hacerse dignos, en su caso, de recibir alguna ayuda pública (El Comercio, 7-10-1924, 8-10-1924 y 8-12-1924). Para completar esta especie de ciclotimia mediático-política, frente al agravamiento de la crisis carbonera a finales de la década va a apoyar las medidas intervencionistas de Primo de Rivera, sobre todo a raíz de la promulgación del Estatuto Hullero en 1927. Incluso se llegará a preconizar la nacionalización de la industria minera, "la base [...] de la independencia de España" (El Comercio, 27-5-1928). También en este propósito encontró -en este caso de forma menos inopinada- la compañía del Sindicato Minero, dado que su líder defendía ya por aquel entonces dicha nacionalización (Llaneza, 1921). Sin embargo, el histórico socialista otorgaba en su proyecto un gran poder en la gestión de las explotaciones a los mineros a través del sindicato, algo que sin duda El Comercio no compartía.

\section{Conclusión}

El diario que nos ocupa tiene una orientación comercial y no política en el sentido partidista porque su negocio directo consiste en vender el mayor número de ejemplares y para ello es muy recomendable aparecer lo más plural que sea posible para no 
molestar a ningún sector del público potencial. Sin embargo, esto no es óbice para que $\mathrm{El}$ Comercio defienda los activos económicos de sus socios, si bien las motivaciones aludidas para esta forma de actuar remiten invariablemente al interés general $\mathrm{y}$, obviamente, evitan que trasluzca el objetivo último. Por lo común esto deriva en una promoción constante del progreso material de la ciudad y la comarca, a la que habría que sumar en lugar destacado la preocupación por la "cuestión social" que emana directamente del miedo de un amplio sector de la burguesía a un estallido revolucionario

Sin embargo, se constata fácilmente que existe una diferencia de grado en el tratamiento de los diferentes asuntos según pertenezcan a una u otra categoría: no se emplea la misma vehemencia, ni se dedica igual cantidad de tiempo o se consagra idéntico espacio a las causas que defiende de oficio, por así decir, que a aquellas en las que existe una implicación directa de una parte de su accionariado. Dentro de este segundo grupo, el de los asuntos por los que se siente especialmente concernido $E l$ Comercio, tiene un lugar destacado la minería. Como se ha indicado, ésta ni siquiera existe en el inmediato hinterland gijonés en esta época y esto constituye un buen indicio de cuál es el provecho que de la misma obtiene. La confirmación viene marcada por otras señales y, muy particularmente, por la circunstancia de que no exista en sus páginas una preocupación por los márgenes de beneficio de las hulleras, más allá de la elemental que permita hacerlas sostenibles, sino que estos se sacrifican de buen grado en aras del incremento de los volúmenes transportados, lo que resulta sumamente conveniente para los negocios navieros de los accionistas del diario.

Como se destacaba en la introducción, resultaría de gran interés que se siguieran estudios respecto a las posiciones que sobre el problema hullero tuvieron otros diarios asturianos en la época, con el fin de comparar, extraer uniformidades y divergencias y poder llegar a conclusiones que permitan contribuir a establecer una parte del mapa de los conglomerados y alianzas empresariales de la burguesía regional.

\section{Referencias bibliográficas}

ADARO Y MAGRO, L. (1911). Los carbones nacionales y la marina de guerra. Madrid: Establecimiento Tipográfico de Ginés Carrión.

ALDECOA, M. et alii (1926). Dictamen oficial sobre la industria hullera en Asturias. Madrid: Imprenta Clásica Española.

ALVARGONZÁLEZ, R. M. ' (1977). Gijón: industrialización y crecimiento urbano. Salinas: Ayalga.

ALVARGONZÁLEZ, R. M. a (1985). Industria y espacio portuario en Gijón. Gijón: Junta del Puerto.

DESVOIS, J.-M. (1977). La prensa en España 1900-1931. Madrid: Siglo XXI.

DÍAZ-FAES INTRIAGO, M. (1979). La minería de la hulla en Asturias. Oviedo: Universidad de Oviedo. 
DÍAZ GONZÁLEZ, M. ${ }^{\mathrm{a}}$ M.; CAMPO, O. (2004). “La ilustración gráfica y la fotografía en la prensa periódica asturiana (1880-1914)". En URÍA, J. Historia de la prensa en Asturias, tomo I, Nace el cuarto poder. La prensa en Asturias hasta la Primera Guerra Mundial. Oviedo: Asociación de la Prensa de Oviedo. p.429-454.

FERNÁNDEZ AVELLO, M. (1976). Historia del periodismo asturiano. Salinas: Ayalga.

FERNÁNDEZ VEGA, C. (2004). “El diario El Comercio (1878-1914)”. En URÍA, J. Historia de la prensa en Asturias, tomo I, Nace el cuarto poder. La prensa en Asturias hasta la Primera Guerra Mundial. Oviedo: Asociación de la Prensa de Oviedo. p. 163-198.

GARCÍA DELGADO, J. L. (1977). “La economía española entre 1900 y 1923”. En Tuñón de Lara, Manuel (dir.). Historia de España, vol. VIII. Barcelona: Ediciones de Bolsillo. p. 407-458.

GARCÍA GARCÍA, J. L. (1996). Prácticas paternalistas: un estudio antropológico sobre los mineros asturianos. Barcelona: Ariel.

ÍNIGO FERNÁNDEZ, L. (2000). Melquiades Álvarez: un liberal en la Segunda República. Oviedo: Real Instituto de Estudios Asturianos.

LLANEZA ZAPICO, M. (1921). Estudio de la industria hullera española y la necesidad de su nacionalización: proyecto de una Ley de bases para la nacionalización de las minas de hulla de España. Oviedo: SOMA.

LLANEZA ZAPICO, M. (1985). Escritos y discursos. Oviedo: Fundación José Barreiro.

MATO, Á., CARMONA, J. L.; ALÍAS, L. A. (2003). Testigo de la historia. 125 años. El Comercio 1878-2003. Gijón: El Comercio.

MORADIELLOS, E. (1986). El Sindicato de los Obreros Mineros de Asturias, 19101930. Oviedo: Univ. de Oviedo.

MUÑIZ SÁNCHEZ, J. (2007). "Prensa local y radicalización política ciudadana: el diario asturiano El Comercio hacia la guerra civil". En Estudios sobre el Mensaje Periodístico, n. ${ }^{\circ}$ 13. Madrid: Servicio de Publicaciones de la Universidad Complutense. p. 481-498.

SIERRA ÁLVAREZ, J. (1990). El obrero soñado: ensayo sobre el paternalismo industrial (Asturias, 1860-1917). Madrid: Siglo XXI.

OJEDA, G. (1985). Asturias en la industrialización española, 1833-1907. Madrid: Siglo XXI.

OLIVEROS, A. L. (1947). Un tribuno español: Melquiades Álvarez y González. La Habana: Ramiro F. Moris.

PORTOLÁ, F. (1918). Topografía médica del concejo de Gijón. Madrid: Real Academia Nacional de Medicina.

SANTULLANO, G. (1978). "La prensa desde 1898 hasta 1920". En ARIAS, A. Historia general de Asturias. Gijón: Silverio Cañada. p. 148-182.

URÍA, J. (coord.) (2004). Historia de la prensa en Asturias. Nace el cuarto poder. La prensa en Asturias hasta la Primera Guerra Mundial. Oviedo: Asociación de la Prensa de Oviedo. 


\section{El autor}

Jorge Muñiz (Oviedo, 1978) es doctor en Historia y ha participado en diferentes proyectos de investigación sobre prensa y minería. El interés por la historia comparada le ha llevado a desarrollar diversas estancias en universidades francesas y a obtener el Doctorado Europeo para posteriormente investigar sobre las minas del Norte de Francia ligado a un centro Paris I/CNRS gracias a un contrato postdoctoral. Sus líneas de trabajo principales son la historia sociocultural e industrial y actualmente es profesor de la Universidad de Oviedo. Sus últimas publicaciones son la biografía de un histórico sindicalista y artículos sobre minería en las revistas Hispania, Cuadernos de Historia Contemporánea, Historia Social y Le Mouvement Social y sobre prensa en Asturias en Estudios sobre el Mensaje Periodístico. 